\title{
Videovigilancia en el Centro Histórico de la Ciudad de México
}

\begin{abstract}
Jordy Micheli"
Laura Islas **

La videovigilancia en la Ciudad de México constituye una de las infraestructuras urbanas importantes que se han construido en los inicios del siglo XXI, en paralelo con una tendencia histórica en la urbanización global. Nace de un proyecto de reorganización del Centro Histórico bajo condiciones de acumulación privada de un actor principal tanto inmobiliario como tecnológico, y se ha extendido al conjunto de la ciudad, dándole un sello actual de modelo de seguridad basada en vigilancia electrónica.
\end{abstract}

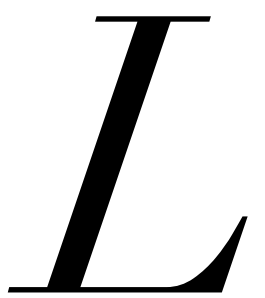

Antecedentes: VideOvigIlancia COMO PROCESO URBANO

A CREACIÓN DE INFRAESTRUCTURA tecnológica urbana de videovigilancia es un signo característico de la coevolución de la ciudad con la sociedad de la información: confirma que la urbanización contemporánea es un proceso histórico marcado por la producción inmaterial mediante tecnologías de información y comunicación y que genera un nuevo modo de vida sintetizado por el cons-

* Profesor-investigador del Departamento de Economía de la Universidad Autónoma Metropolitana-Azcapotzalco, México.

** Doctorante del posgrado en Diseño en la Universidad Autónoma Metropolitana-Azcapotzalco, México. tructo de sociedad de la información. ${ }^{I}$ El crecimiento de la videovigilancia es indisoluble con la política pública de la seguridad y representa un mercado en expansión: se calcula que el mercado mundial de estos sistemas tecnológicos crecerá de ir.5 miles de millones de dólares, en 2008, a 37.5 miles de millones en 2015. Hay 4 mil cámaras en Manhattan, Io mil en Chicago y medio millón en Londres. ${ }^{2}$

Las tecnologías que se asocian a las funciones de vigilancia han ampliado a tal grado su penetración en las sociedades, ciudades, empresas y en las ideologías de Estado, que han convocado a nuevas interpretaciones desde el ámbito de las ciencias sociales. ${ }^{3} \mathrm{Si}$ bien seguridad y vigilancia han sido históricamente procesos presentes en las sociedades, hoy ocupan un 


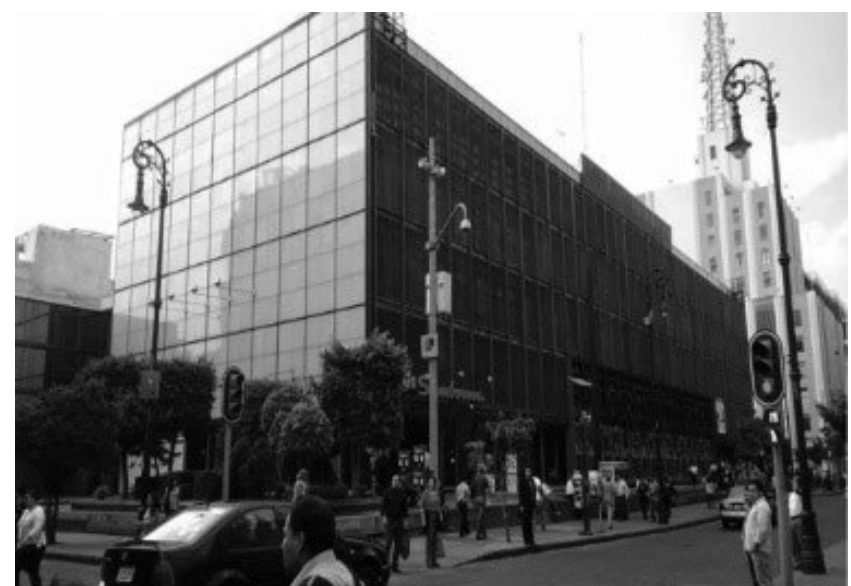

Edificio NAFIN, actualmente Instituto de Tecnología Telmex. Primera cámara colocada en el Centro de la Ciudad. Foto: Laura Islas.

lugar central en la nuestra. Aparecen de la mano de infraestructuras y dispositivos digitales de todo tipo y conforman un nuevo proceso de concentración de riqueza y actividades en la urbe. ${ }^{4}$ Los sistemas de videovigilancia son el ejemplo más evidente: ensambles tecno-sociales que contienen artefactos, redes y personal especializado que conforman las nuevas infraestructuras urbanas.

La videovigilancia constituye un sistema de producción de servicios que une aspectos tecnológicos con sociales en territorios específicos y como tal debe ser comprendido en tanto fenómeno urbano. Los aspectos tecnológicos son en esencia las cámaras y su estructura de colocación, unidas por una red de fibra óptica y los centros de observación de las imágenes que captan las cámaras. También forma parte de este sistema la información generada y su almacenamiento digital bajo pautas de big data.

El sistema social es el que hace operativo y socialmente útil todo el sistema tecnológico, así que comprende al personal directamente relacionado con la operación y respuesta, en su caso, como con la forma en que socialmente estos dispositivos son introducidos y aplicados en la vida urbana cotidiana. De igual modo, las leyes que permiten y fomentan la videovigilancia como proceso que forma parte de la vida urbana son parte social del sistema.

Aquí cabe decir que la "seguridad" ofrecida mediáticamente como característica mensurable, y por tanto mercancía política, pareciera ser producto de las nuevas pautas de vigilancia electrónica, pero no debe perderse de vista que la seguridad es un proceso con actores e intereses que produce sus propios sistemas para el mercado. ${ }^{5}$ La seguridad es parte de la vida económica y política, no el resultado de decisiones de los actores de la política urbana o nacional.

\section{Centro Histórico de la Ciudad de México: VIDEOVIGILANCIA BAJO LA ACUMULACIÓN PRIVADA}

La videovigilancia en la Ciudad de México tiene ya una presencia de $\mathbf{5}$ mil cámaras y un sistema organizativo de centros de comando en varios puntos de la capital. Es la columna vertebral de una reorganización de la vigilancia pública, en combinación con la privada, y constituye una de las infraestructuras urbanas importantes que se han construido en los inicios del siglo XXI en la ciudad, en paralelo con una tendencia histórica en la urbanización global.

La reorganización urbana, gentrificación, del Centro Histórico de la Ciudad de México ( $\mathrm{CHCM}$ ) es el proceso que explica y condiciona el fenómeno de creación del sistema tecnológico y social de la videovigilancia en el Distrito Federal. La gentrificación es un proceso urbano contemporáneo que explica la revalorización mercantil de territorios con densidad de infraestructura histórica y poca habitabilidad social, y en el caso particular del снсм la crisis territorial de los años noventa fue producto de décadas de deterioro físico de la vivienda a causa de la política de "rentas congeladas" junto con el efecto devastador del sismo de ig85, que despobló ese territorio y lo condicionó a un estatus de centro económico tradicional pero carente de actividades dinámicas y de conductas poblacionales acordes con el dinamismo general que mostraban otros territorios de la ciudad.

En 1997, la Asamblea de Representantes, un órgano político de representación local del Distrito Federal, aún limitado en sus competencias en ese entonces, organizó y dejó una propuesta urbanística para la renovación del Centro Histórico. El gobierno local en 2000 generó las primeras acciones que darían viabilidad a dicha propuesta, facilitando la venta de inmuebles de valor histórico al empresario Carlos Slim, junto con una reorganización institucional en la gobernanza del CHCM.

Las acciones de este gobierno local no se dieron en el vacío, pues deben verse como parte de un proceso durante años previos en que se intentaron diversas medidas de renovación y rescate del territorio urbano 

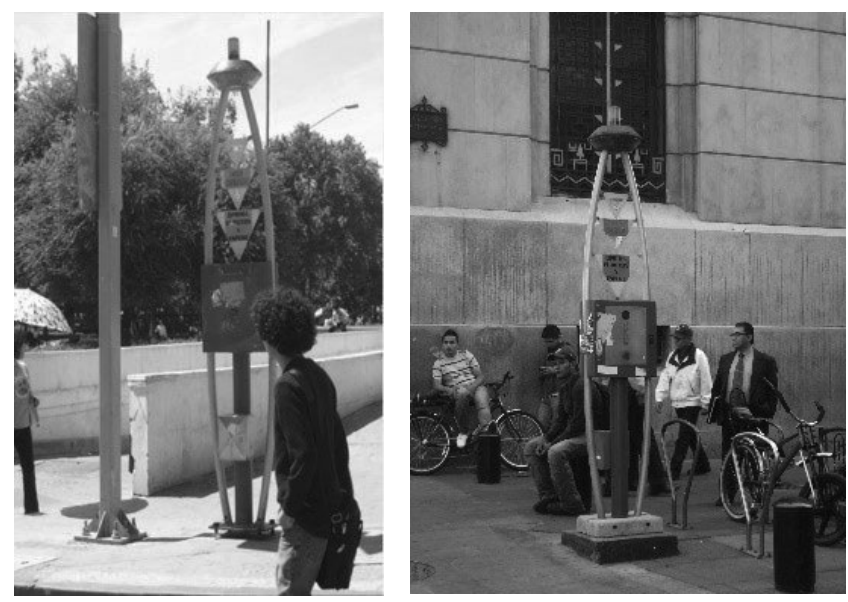

Centinelas. Primer dispositivo del sistema de videovigilancia en la Ciudad de México. Foto: Laura Islas.

en cuestión. Sin embargo, la nueva etapa, iniciada a finales del siglo y con el impulso de la jefatura de gobierno, permitieron dar cauce a la asociación público-privada que dinamizó la reorganización del Centro Histórico.

El poder empresarial que forma parte de esta operación de Estado apareció como la facilitadora tecnológica, pero tuvo también un interés de vigilancia y ejercicio de poder en territorios que si bien son públicos, se revalorizan en un modelo de asociación públicoprivado que no ha requerido regulación. El motor fue una acumulación privada acelerada: se trata básicamente de la compra, en 200o, de una centena de inmuebles de valor histórico en una estrategia de empresas de Carlos Slim dedicadas al mercado inmobiliario en gran escala, con la finalidad de ocupar espacios productivos en el campo de servicios dominados por el mismo empresario y en un territorio de alto valor desde el punto de vista urbano.

Se incluyeron emblemáticos inmuebles como la Torre Latinoamericana, Nacional Financiera o la antigua Bolsa de Valores. En particular, la manzana de Venustiano Carranza, Isabel la Católica, Uruguay y Bolívar pasó a ser propiedad del empresario, y a partir de ese núcleo territorial, el Centro Histórico se convirtió en sede de empresas que previamente habían estado situadas en Cuicuilco, al sur de la ciudad (Inbursa, Inttelmex, Sección Amarilla, Telmex); el Centro Histórico también fue ocupado para tiendas del empresario. Las primeras cámaras fueron colocadas en 2003 en la manzana citada, en donde se instaló el Instituto Tecnológico Telmex, dentro del cual se ubicó el primer centro de monitoreo de la red de videovigilancia instalada inicialmente en el CHCM.
Las primeras cámaras de monitoreo urbano que se instalaron en la vía pública en la Ciudad de México actuaron como apoyo al sistema de semáforos y datan de inicios de los años ochenta del siglo pasado. Este incipiente sistema de televigilancia fue usado paulatinamente para vigilar eventos culturales y deportivos, marchas y otros aconteceres sociales, por parte de la Secretaría de Seguridad Pública del Distrito Federal. En 2003 se instalaron dos nuevos sistemas en el CHCM: el sistema de Centinelas y las cámaras de videovigilancia (CCTV); ambas tenían un objetivo exploratorio en el marco de las tendencia de acumulación privada y desarrollo social del CHCM.

Los Centinelas fueron i5̌ equipos electrónicos de observación, emergencia e información general que podían ser usados interactivamente en audio y video por el público. El concepto básico es el "botón de pánico" conectado al Centro de Atención Inmediata al Público (CAIP) y al Puesto de Mando del Centro Histórico. Ese centro de recepción recibía también las llamadas de emergencia del o6o de la ciudad.

Los botones de pánico permitieron atender emergencias, pues al presionar un botón se accionaba una cámara de video integrada en la parte media y cuatro cámaras más ubicadas en la parte superior para cubrir todo el radio de influencia posible del evento. Además, permitían enviar imagen y sonido para orientar al ciudadano en una situación de emergencia si así lo reque-
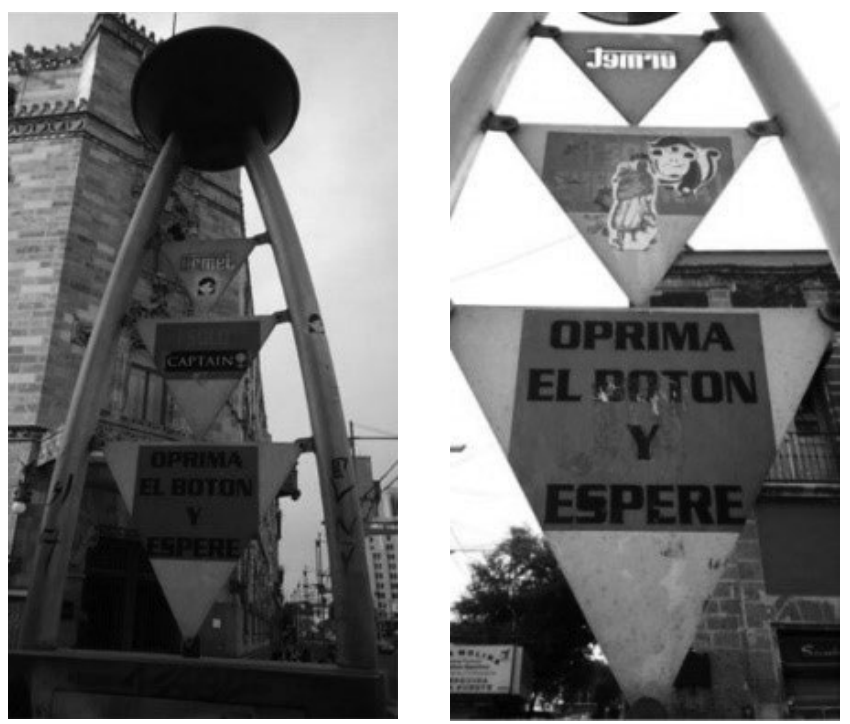

Centinelas botón de mergencia S.O.S. con señal al CAIP. Foto: Laura Islas. 

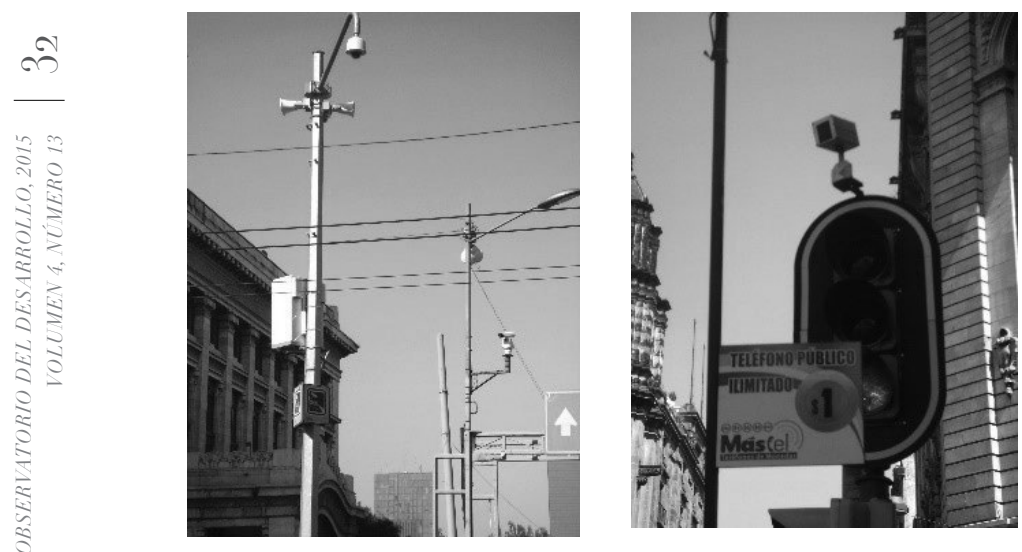

Dispositivos de videovigilancia. Proyecto Bicentenario Ciudad Segura. Fotos: Laura Islas.

ría y la información era grabada y almacenada por tiempo indefinido. El botón de pánico era ya una tecnología de seguridad ampliamente utilizada mundialmente, la innovación en el caso de la ciudad fue precisamente explorar su utilidad, situación que es la que define su papel real como tecnología de seguridad. La aceptación social de los mecanismos tecnológicos de seguridad es un tema relevante, a modo de contraste, esta tecnología no fue aceptada en Ciudad Juárez. ${ }^{6}$

En cuanto a los dispositivos de cámaras de videovigilancia, fueron instalados roo y colocados en las esquinas del Снсм con mayor afluencia y evidencias de mayores riesgos de inseguridad. Su emplazamiento físico fue en semáforos y paredes de edificios, a una altura normalmente difícil de registrar por los transeúntes. Las cámaras de video funcionan a través de un giro horizontal de 360 grados y vertical de i8o grados, con una capacidad de acercamiento de 200 metros para la identificación de placas y de 5 o metros para rasgos faciales. La filmación diaria de dichos aparatos es almacenada durante un tiempo indefinido para su uso posterior.

El lugar de observación de las imágenes de las cámaras era el Puesto de Mando del Centro Histórico, ubicado en el número i5 de la Calle Héroes del 57, donde también se atendían las llamadas del número de emergencia o6o que se generaban en toda la ciudad. Este puesto de mando tenía a su cargo joo elementos de las policías Bancaria e Industrial, Auxiliar, Preventiva y de la Unidad de Protección Ciudadana, quienes resguardaban el área de i6o manzanas del llamado "Primer Cuadro" de la ciudad.

Este puesto de mando, como centro de servicios de vigilancia que combinó llamadas telefónicas del o6o y monitoreo de las nuevas tecnologías, generó informaciones territoriales que permitieron determinar las colonias y calles más peligrosas de la ciudad y poner cámaras en estos puntos en la actualidad, en una etapa siguiente. En la actualidad el centro de la ciudad cuenta con 228 cámaras de seguridad y los Centinelas fueron sustituidos por cámaras de seguridad, ${ }^{7}$ debido a que resultaron más viables por su amplia cobertura no sólo para ser utilizada en el Centro Histórico, sino en toda la ciudad.

En 2008 se aprobó y publicó la Ley que Regula el Uso de la Tecnología para la Seguridad Pública del Distrito Federal en la que se definió la regulación de la ubicación y utilización de la información, y se estableció como uno de los objetos de la ley: "Contribuir al mantenimiento del orden, la tranquilidad y estabilidad en la convivencia así como prevenir situaciones de emergencia o desastre e incrementar la seguridad ciudadana". El artículo I 4 señala: "La instalación de equipos y sistemas tecnológicos, se hará en lugares en los que contribuya a prevenir, inhibir y combatir conductas ilícitas y a garantizar el orden y la tranquilidad de los habitantes del Distrito Federal". ${ }^{8}$

Una siguiente fase se da a partir de 20I0, en que las acciones de reorganización del Centro Histórico se han trasladado hacia lo que se llama el Perímetro B del mismo. Desde la perspectiva del territorio del Centro Histórico, la iniciativa de la acumulación privada de Carlos Slim se extiende hacia una parte del Perímetro B: la que cubre la zona de la Alameda Central y las manzanas que se extienden de allí hacia las avenidas Río de la Loza, entre Bucareli y el Eje Central, en dirección al sur.

Esta orientación del eje de acumulación tiene una motivación estratégica para la empresa: se trata de la zona en la cual se encuentra la Torre de Telmex, centro neurálgico de la red de telecomunicaciones, que por su carácter cuasi-monopólico es prácticamente nacional. No es solamente esta instalación, sino su enclave en una pequeña zona valorizada por los inmuebles de la que fuera la pequeña ciudad industrial de Ernesto Pugibet a inicios del siglo xx. Por tanto, se puede seguir el desarrollo de la expansión de la acumulación privada hacia esta subzona del Perímetro B, mediante la evolución de la infraestructura de videovigilancia.

El gobierno de la ciudad lanzó también en 20I0 el Programa Bicentenario para expandir el sembrado de cámaras de videovigilancia asociado a la creación de un sistema tecnosocial de seguridad que cubre al conjunto de la ciudad: el Proyecto Bicentenario Ciudad Segura es un sistema integrado por 8,080 cámaras que ya monitorean el territorio de forma fija y en fuentes móviles, conectadas a un Centro de Mando Principal llamado C-4, a cinco centros regionales y dos móviles denominados $\mathrm{C}$-2, que se hacen cargo tanto del proce- 


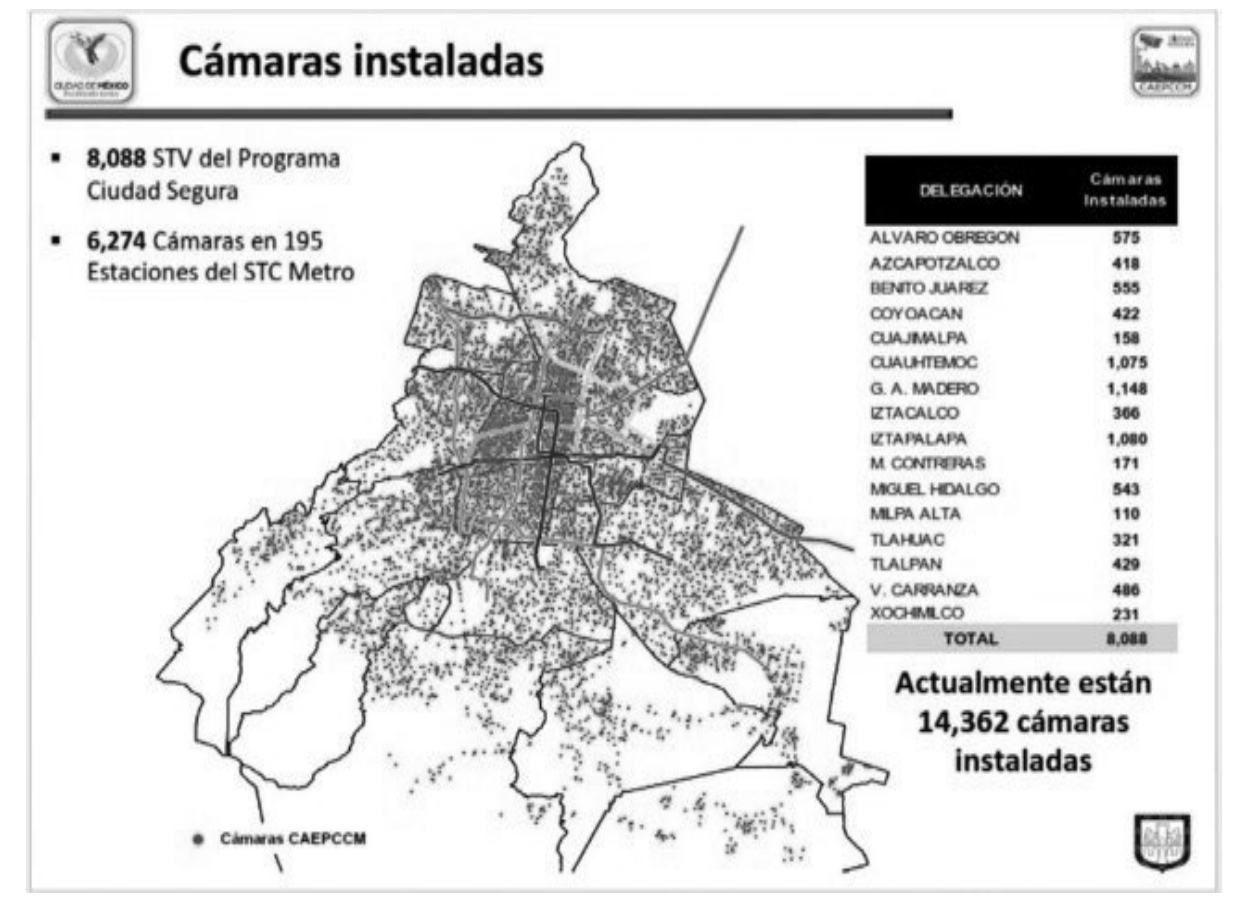

Mapa del sembrado de cámaras en la Ciudad de México. Fuente: CAEPCCM.

samiento de llamadas de los ciudadanos, como de la vigilancia, apoyándose en la red de telecomunicaciones del Metro.

En resumen, bajo el Proyecto Ciudad Segura de la administración anterior (Marcelo Ebrard) se sembraron 8 mil cámaras, de las cuales cerca de 4 mil en las estaciones del Metro y 2,38o en los propios vagones del sistema de transporte colectivo. En la administración actual (Miguel Mancera), se anunció la expansión de la videovigilancia a 7 mil cámaras más: 3 mil para las zonas habitacionales de alta densidad demográfica, dos mil 33ı para puntos con alta incidencia delictiva, 5oo para control de tránsito, 369 para instalaciones estratégicas, 200 para reconocimiento de placas vehiculares, 300 para el carril confinado del Metrobus y 300 más en zonas rurales y de conservación.

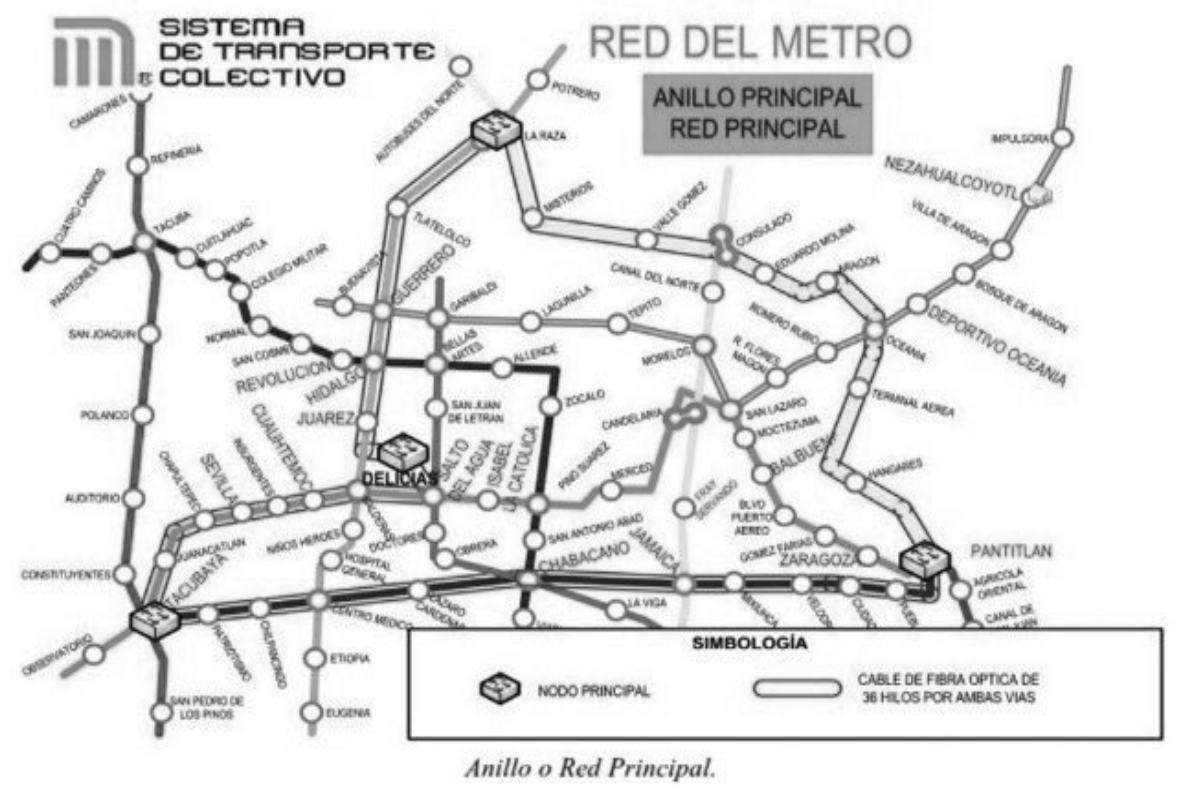

Anillo de la red principal de fibra óptica del STC Metro en la Ciudad de México. Fuente: Servicio de Transporte Colectivo Metro. 


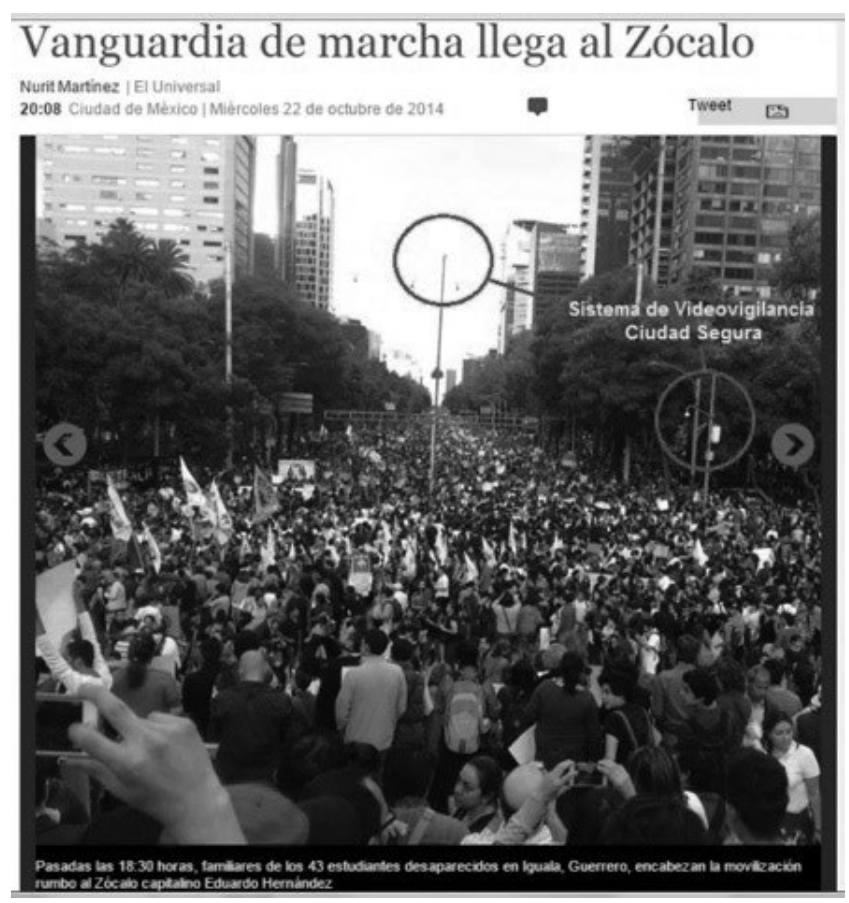

Arribo de manifestantes al Zócalo de la Ciudad de México. Fuente: Nuri Martínez, Eduardo Hernández octubre de 2014), El Universal.

Este texto ha querido servir para apuntar hacia la singularidad de lo local (Ciudad de México) en un proceso urbano de índole general: la construcción de infraestructuras de videovigilancia. Esta singularidad es un proyecto de reorganización del Centro Histórico bajo condiciones de acumulación privada de un actor principal tanto inmobiliario como tecnológico. Los aprendizajes obtenidos por las autoridades locales han facilitado la extensión del modelo tecnosocial de seguridad y vigilancia electrónica del CHCM, al conjunto de la ciudad.

Salta a la vista la necesidad de generar estudios sobre esta nueva infraestructura urbana de carácter informático y comunicacional, incorporándola como un componente nuevo de la racionalidad urbana. Será la llave para entender nuevas configuraciones de lo público-privado, políticas de seguridad, integración de redes tecnológicas y en general, nuevos modos de vida urbanos.

\section{- notas - -}

' Jordy Micheli (2012), Telemetrópolis: explorando la ciudady su producción inmaterial, Barcelona, GEDISA-UAM.

2 Keith Proctor (2013), "The Great Surveillance Boom", en Fortune Magazine, disponible en http://fortune.com/2013/0/26/thegreat-surveillance-boom/ (consultado el i5 de noviembre de 2014).

${ }^{3}$ Armand Mattelart (2009), Un mundo vigilado, Barcelona, Paidós; Lyon, David (200I), Surveillance Society, Open University Press; Lyon, David (2007), Surveillance Studies, an Overview, Cambridge, Polity; Graham, Stephen (2010), Villes sous Controle, Paris, La Decouverte.

${ }^{4}$ Francois Ascher (1995), Metapolis, Paris, Odile Jacob.

${ }^{5}$ Kirstie Ball y Laureen Snider (2013), The Surveillance-Industrial Complex, Londres, Routledge; Rallo Lombarte, Artemi
(20II) "Videosurveillance, Data Protection and Urban Security", Democracia \& Sicurezza, año I, en http:/www.democraziaesicurezza.it/Saggi/Videosurveillance-data-protection-and-urbansecurity (consultado el 2 de enero de 2015 ).

${ }^{6} \mathrm{http} / /$ diario.mx/Local/201/4-o7-13_defed22a/botones-depanico-aqui-un-fracaso-millonario/

7 Secretaría de Seguridad Pública del Distrito Federal, marzo de 20I4.

${ }^{8}$ Gobierno del Distrito Federal (2008), Gaceta Oficial del Distrito Federal, Distrito Federal, 27 de octubre, en http://mexico.justia.com/estados/df/leyes/ley-que-regula-el-uso-de-tecnologia-para-la-seguridad-publica-del-distrito-federal/ (consultado el 29 de noviembre de 2014). 